\title{
Improved Mechanical Properties of Compatibilized Polypropylene/Polyamide-12 Blends
}

\author{
Nora Aranburu and José Ignacio Eguiazábal \\ Departamento de Ciencia y Tecnología de Polímeros and POLYMAT, Facultad de Ciencias Químicas, \\ Universidad del País Vasco UPV/EHU, P.O. Box 1072, 20080 Donostia, Spain
}

Correspondence should be addressed to José Ignacio Eguiazábal; josei.eguiazabal@ehu.es

Received 6 November 2014; Accepted 2 March 2015

Academic Editor: Tianxi Liu

Copyright (C) 2015 N. Aranburu and J. I. Eguiazábal. This is an open access article distributed under the Creative Commons Attribution License, which permits unrestricted use, distribution, and reproduction in any medium, provided the original work is properly cited.

\begin{abstract}
Compatibilized blends of polypropylene (PP) and polyamide-12 (PA12) as a second component were obtained by direct injection molding having first added $20 \%$ maleic anhydride-modified copolymer (PP-g-MA) to the PP, which produced partially grafted PP (gPP). A nucleating effect of the PA12 took place on the cooling crystallization of the gPP, and a second crystallization peak of the gPP appeared in the PA12-rich blends, indicating changes in the crystalline morphology. There was a slight drop in the PA12 crystallinity of the compatible blends, whereas the crystallinity of the gPP increased significantly in the PA12-rich blends. The overall reduction in the dispersed phase particle size together with the clear increase in ductility when gPP was used instead of PP proved that compatibilization occurred. Young's modulus of the blends showed synergistic behavior. This is proposed to be both due to a change in the crystalline morphology of the blends on the one hand and, on the other, in the PA12-rich blends, to the clear increase in the crystallinity of the gPP phase, which may, in turn, have been responsible for the increase in its continuity and its contribution to the modulus.
\end{abstract}

\section{Introduction}

Polymer blending has been extensively used over the last few decades to produce new polymeric materials which combine the individual attributes of the component neat polymers [1]. However, compatibilization is usually necessary in polymer blends [2] due to the immiscibility and incompatibility of most polymer pairs [3]. Compatibilization improves the blend morphology, enhances interfacial adhesion, and consequently improves the performance of the blend [4].

Blends of polypropylene (PP) with polyamides (PAs) are interesting because they allow the thermomechanical properties of the PAs to be combined with the processability of the PP [5]. However, these blends are incompatible due to the dissimilar polar-non-polar nature of PAs and PP, respectively. Therefore, compatibilization was attempted mainly through modifying the PP with maleic anhydride (MA) [6-18], acrylic acid (AA) $[13,16,17]$, and glycidyl methacrylate (GMA) [15, 19] groups. These groups are able to react with the terminal amine groups in the PA, forming graft copolymers which locate at the interfaces. These copolymers should reduce the interfacial tension and coalescence rate and improve interfacial adhesion between the components [8].

Polyamide-12 (PA12) has longer aliphatic chains, as well as a lower melting point and water sorption than other PAs, such as PA6 and PA66. PA12 also shows greater flexibility, resistance to pressure and impact, and good mechanical properties at extreme temperatures, thermal stability, and chemical resistance [20]. PP is easy to process and shows good strength and solvent resistance. Despite this, papers dealing with the compatibilization of PP/PA12 blends are scarce. The crystallization and morphology of these blends [21,22] and their thermal degradation and crystallization [14] have been partially studied. When kneading-compression molding was used $[8,9]$, a critical compatibilizer concentration was identified relative to the particle size, but the elongation at break did not improve as a result. The morphology and the elongation at break improved in an 80/20 PA12/PP blend modified with either PP-g-MA or PP-g-AA, with the former proving the better compatibilizer [17]. 
For this study, the PP was first modified by a PP-gMA copolymer to obtain gPP and the gPP/PA12 blends were prepared directly during the plasticization step of an injection molding process through the whole composition range. Next, they were characterized by dynamic-mechanical thermal analysis (DMTA) and differential scanning calorimetry (DSC). The compatibilization level reached was tested and discussed by the morphology (scanning electron microscopy, SEM) and the tensile properties before and after compatibilization.

\section{Experimental}

The polymers used in this work were an isotactic polypropylene (PP), Isplen PP070 G2M, by Repsol YPF, and a polyamide-12 (PA12), Rilsan AMNO TLD, by Arkema. The maleated polypropylene (PP-g-MA) was Fusabond PMZ203D, supplied by DuPont, with $0.74 \%$ maleic anhydride content (min: $0.55 \%$; max: 1.15\%). Drying before processing was performed at $50^{\circ} \mathrm{C}$ in an air circulation oven for $4 \mathrm{~h}$ for PP-g-MA and at $80^{\circ} \mathrm{C}$ in a vacuum oven for $24 \mathrm{~h}$ in the case of PA12.

To obtain the compatibilized blends, first PP and PPg-MA were mixed by extrusion in an $80 / 20$ proportion, as explained below. Then, the PP/PP-g-MA blend (gPP hereafter) was directly mixed-injection molded with PA12.

The mixing of PP and PP-g-MA to obtain gPP was performed in a Collin ZK25 corotating twin screw extruderkneader. The screw diameter and the L/D ratio were $25 \mathrm{~mm}$ and 30 , respectively. A melt temperature of $200^{\circ} \mathrm{C}$ and a screw rotation speed of $200 \mathrm{rpm}$ were used. The extrudates were cooled in a water bath and pelletized. The compatibilized gPP/PA12 and uncompatibilized PP/PA12 blends as a reference were obtained by direct mixing-injection molding of the components. Blending was carried out during the plasticization step of the injection molding process developed in a Battenfeld BA-230E reciprocating screw injection molding machine to obtain tensile (ASTM D638, type IV, thickness $1.84 \mathrm{~mm}$ ) and impact (ASTM D256, thickness $3.1 \mathrm{~mm}$ ) specimens. The neat polymers were also molded as reference materials. The screw of the plasticization unit was a standard screw with a diameter of $18 \mathrm{~mm}$, an $\mathrm{L} / \mathrm{D}$ ratio of 17.8 , and a compression ratio of 4 . The melt temperature was $200^{\circ} \mathrm{C}$ and the mold temperature was $15^{\circ} \mathrm{C}$. The injection speed and pressure were $10.2 \mathrm{~cm}^{3} \cdot \mathrm{s}^{-1}$ and $2750 \mathrm{bar}$, respectively. The specimens were left to condition for $24 \mathrm{~h}$ in a dessicator before analysis or testing.

Dynamic mechanical analysis was carried out in a TA Instruments DMA Q800 apparatus that provided the plot of the loss modulus $\left(E^{\prime \prime}\right)$ against temperature. The scans were carried out from -100 to $140^{\circ} \mathrm{C}$ at a constant heating rate of $4^{\circ} \mathrm{C} / \mathrm{min}$ and at a frequency of $1 \mathrm{~Hz}$. The melting behavior was studied by DSC using a Perkin-Elmer DSC-7 calorimeter calibrated with an Indium standard. A heating scan was made from $30^{\circ} \mathrm{C}$ to $200^{\circ} \mathrm{C}$ at a heating rate of $20^{\circ} \mathrm{C} / \mathrm{min}$ and the subsequent cooling scan was made in the same conditions. The melting temperature $\left(T_{m}\right)$ and enthalpy $\left(\Delta H_{m}\right)$ of PP and PA12 were determined from the heating scans using the peak maximum and area, respectively. As the melting peaks of the PP and PA12 in the blends partially overlapped, the partial areas were used in order to estimate the crystallinity of each component of the blend. To do this, the total area was first calculated and then a separating line was drawn from the minimum between the melting peaks to the baseline in order to calculate the partial area belonging to each component of the blend. The crystallization temperatures $\left(T_{c}\right)$ were determined from the cooling scans using the minimum temperatures of the crystallization exotherms. The crystallinity of PP and PA12 was calculated assuming a melting enthalpy of $209 \mathrm{~J} / \mathrm{g}$ for $100 \%$ crystalline PP [11] and 209.2 J/g for $100 \%$ crystalline PA12 [23], respectively. XRD patterns were recorded in an X'pert X-ray diffractometer operating at $40 \mathrm{kV}$ and $40 \mathrm{~mA}$, using a Ni-filtered $\mathrm{K}_{\alpha} \mathrm{Cu}$ radiation source.

Cryogenically broken surfaces of the tensile specimens of the blends were observed, after gold-coating, by scanning electron microscopy (SEM), using a Hitachi S-2700 electron microscope operated at an accelerating voltage of $15 \mathrm{kV}$.

Tensile testing was carried out using an Instron 4301 machine at a cross-head speed of $10 \mathrm{~mm} / \mathrm{min}$ and at $23 \pm 2^{\circ} \mathrm{C}$ and $50 \pm 5 \%$ relative humidity. The mechanical properties (yield strength and ductility, measured as the elongation at break) were determined from the load-displacement curves. Young's modulus was determined by means of an extensometer at a cross-head speed of $1 \mathrm{~mm} / \mathrm{min}$. A minimum of five specimens were tested for each reported value.

The orientation of the injection molded specimens was estimated by means of birefringence measurements carried out using a Metricon Model 2010 equipped with an infrared laser with a wavelength of $1550 \mathrm{~nm}$. The samples were prepared by sectioning the central part of the specimens with a Leica 1600 microtome.

The density of the blends was determined by the displacement method in a Mirage SD-120L electronic densitometer using butyl alcohol as the immersion liquid. The estimated resolution was $0.0003 \mathrm{~g} / \mathrm{cm}^{3}$.

\section{Results and Discussion}

3.1. Phase Behavior. The amorphous phase behavior of the gPP/PA12 blends was studied by dynamic mechanicalthermal analysis (DMTA). The plots of selected compositions are shown in Figure 1 and the corresponding $T_{g}$ values are shown on Table 1 . The $T_{g}$ values of the PP blends showed similar trends. Figure 1 shows that irrespective of the composition of the blend, two glass transitions always appeared close to those of pure gPP and PA12, indicating the existence of two phases. No significant trend is observed in the $T_{g}$ of the PA12 in the blends, but a slight increase is observed in the $T_{g}$ of gPP in the PA12-rich blends. This slight increase also occurred in the PP blends, which makes it more significant. This increase will be discussed later and is unlikely to be due to the presence of slight amounts of PA12 resulting from a compatibilization reaction, because it also appeared in the PP blends and, besides, it is known that the different polarity of both components causes full immiscibility [8]. 
TABLE 1: Glass transition temperatures of the gPP/PA12 blends. The average standard deviation is $1^{\circ} \mathrm{C}$.

\begin{tabular}{lcc}
\hline $\begin{array}{l}\text { Composition } \\
\text { gPP/PA12 }\end{array}$ & gPP & $T_{g}\left({ }^{\circ} \mathrm{C}\right)$ \\
\hline $100 / 0$ & 8 & PA12 \\
$85 / 15$ & 8 & - \\
$75 / 25$ & 8 & 51 \\
$60 / 40$ & 8 & 49 \\
$50 / 50$ & 9 & 51 \\
$40 / 60$ & 10 & 49 \\
$25 / 75$ & 10 & 49 \\
$15 / 85$ & 9 & 51 \\
$0 / 100$ & - & 49 \\
\end{tabular}

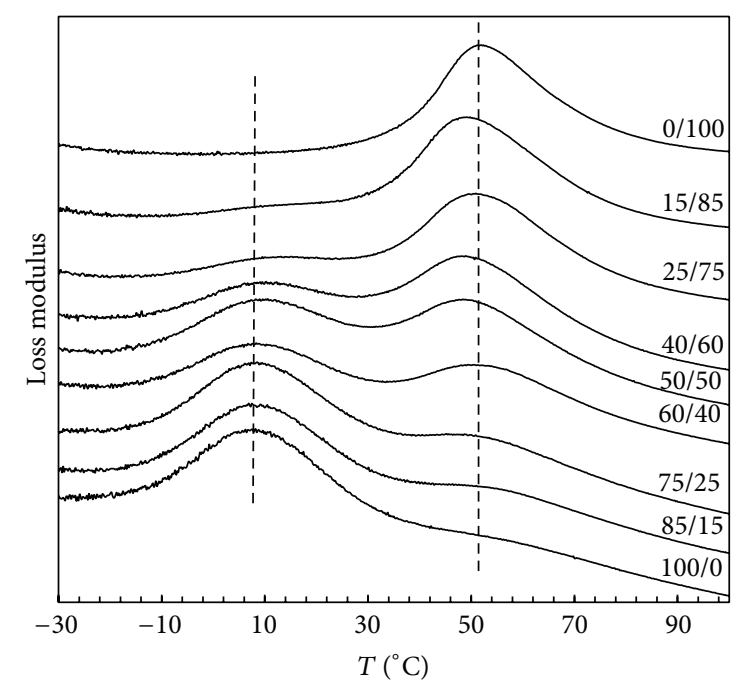

FIGURE 1: Loss modulus curves of the gPP/PA12 blends and the neat polymers.

The melting $\left(T_{m}\right)$ and crystallization $\left(T_{c}\right)$ temperatures of the blends, studied by DSC, are shown in Table 2 . The $T_{m} s$ of the PP blends are not shown because, as in other works $[14,24]$, they were very similar to those of the gPP blends. It was the same in the case of the $T_{c}$. As expected $[11,14,25]$ and reflected on Table 2, the values for the two $T_{m} s$ are similar to those of the corresponding pure polymers. The same was observed for the $T_{c}$ of the PA12 which remained almost constant throughout changes in the blend composition. The $T_{c}$ of the gPP was slightly higher than that of pure gPP, due to a nucleation effect of the already solid PA12 particles on crystallization of the PP, as previously reported in a PP/PA12 80/20 blend [24] and in other PP/PA blends [19, $26,27]$. However, in the PA12-rich compositions, a second $T_{c}$ appeared at a lower temperature. In compatibilized blends, crystallization of the PA6 was also observed to occur over a wider temperature range [28]. This additional crystallization indicates that the crystalline morphology of (at least) the gPP may have changed upon blending.

The crystalline content of each component in the blends was calculated from the corresponding melting heat values
TABLE 2: Melting and crystallization temperatures of gPP and PA12 in the blends. The average standard deviation is $0.5^{\circ} \mathrm{C}$.

\begin{tabular}{lcccc}
\hline $\begin{array}{l}\text { Composition } \\
\text { gPP/PA12 }\end{array}$ & \multicolumn{2}{c}{$T_{m}\left({ }^{\circ} \mathrm{C}\right)$} & \multicolumn{2}{c}{$T_{c}\left({ }^{\circ} \mathrm{C}\right)$} \\
\hline $100 / 0$ & 169.0 & - & 110.5 & - \\
$85 / 15$ & 169.0 & 180.0 & 112.5 & 145.0 \\
$75 / 25$ & 170.0 & 182.0 & 112.0 & 144.5 \\
$60 / 40$ & 169.0 & 181.5 & 112.0 & 144.0 \\
$50 / 50$ & 169.0 & 180.0 & 113.0 & 145.5 \\
$40 / 60$ & 169.0 & 180.5 & $104.5 / 112.5$ & 144.0 \\
$25 / 75$ & 169.0 & 180.5 & $104.5 / 110.5$ & 145.0 \\
$15 / 85$ & 168.0 & 180.0 & 104.5 & 145.0 \\
$0 / 100$ & - & 181.0 & - & 144.5 \\
\hline
\end{tabular}

TABLE 3: Crystallinity of the components in the gPP/PA12 and $\mathrm{PP} / \mathrm{PA} 12$ blends. The average standard deviation is $5 \%$.

\begin{tabular}{lcccc}
\hline \multirow{2}{*}{ Composition } & \multicolumn{4}{c}{ Crystallinity (\%) } \\
& \multicolumn{2}{c}{ gPP/PA12 } & \multicolumn{2}{c}{ PP/PA12 } \\
& gPP & PA12 & PP & PA12 \\
\hline $100 / 0$ & 45 & - & 45 & - \\
$85 / 15$ & 45 & 15 & 45 & 15 \\
$75 / 25$ & 45 & 20 & 45 & 15 \\
$60 / 40$ & 45 & 20 & 45 & 15 \\
$50 / 50$ & 50 & 20 & 60 & 20 \\
$40 / 60$ & 55 & 20 & 60 & 20 \\
$25 / 75$ & 65 & 20 & 75 & 20 \\
$15 / 85$ & 75 & 25 & 55 & 25 \\
$0 / 100$ & - & 30 & - & 30 \\
\hline
\end{tabular}

obtained from the DSC plots and the results are shown in Table 3. It was also tested by X-ray diffraction but the two diffraction peaks almost fully overlapped. As can be seen in Table 3 , the crystalline content of the PA12 decreased slightly in the blends. That of the gPP phase remained constant in the gPP-rich blends but it clearly increased in the PA12-rich compositions. This increase in the crystallinity of the gPP in PA12-rich blends also occurred in the PP blends; this was also observed in another PA6/PP blend [29]. However, in this study, these changes were accompanied by the appearance of the new $T_{c}$ peak. All of these changes are consistent with the increase in $T_{g}$ observed in the gPP (shown in Table 1) and are believed to be responsible for it. They may also have some effect on the mechanical properties of the blends.

3.2. Phase Morphology. The SEM micrographs of the cryogenically fractured surfaces of the $75 / 25,60 / 40,40 / 60$, and 25/75 gPP blends are shown in Figures 2(a)-2(d), respectively, and those of the uncompatibilized blends with PP are shown in Figures 3(a)-3(d), as a reference. The micrographs of Figures 3(a) and 3(c) were taken with an incidence angle of $40^{\circ}$ and those of Figures 3(b) and 3(d) at an angle of $0^{\circ}$. It can be seen that the PP blends in Figure 3 show a biphasic and coarse (typically $2-5 \mu \mathrm{m}$ ) morphology which is consistent with their immiscibility. Moreover, the surfaces 


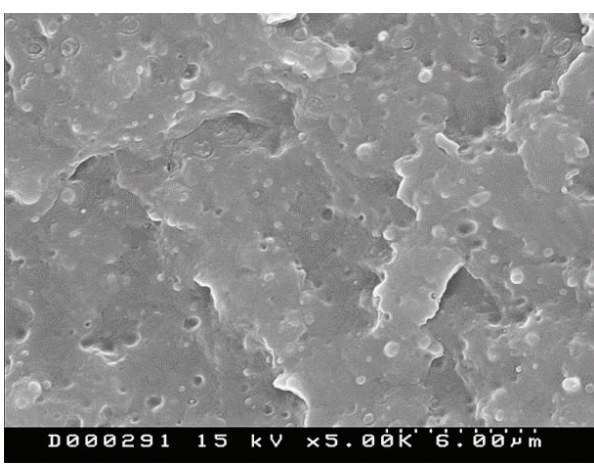

(a)

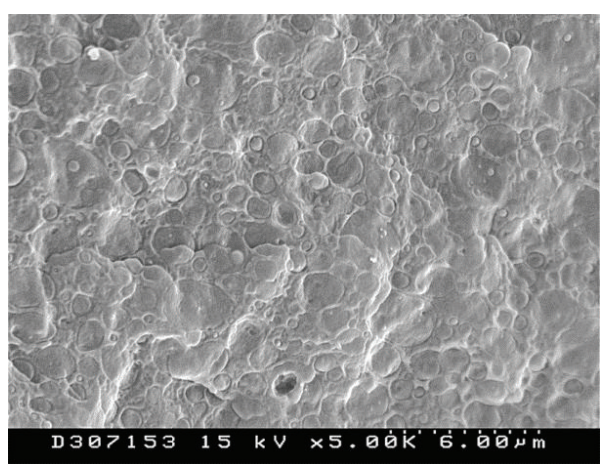

(c)

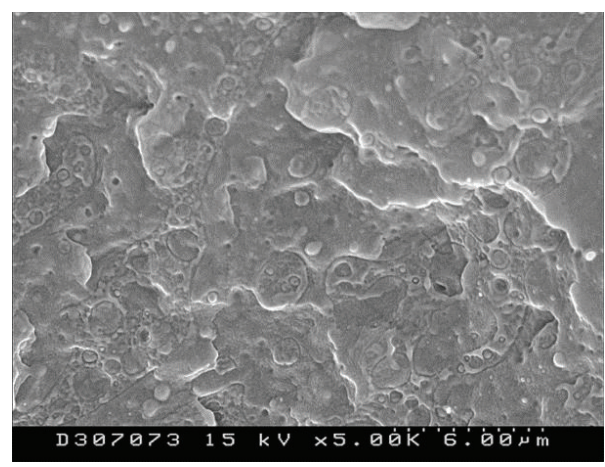

(b)

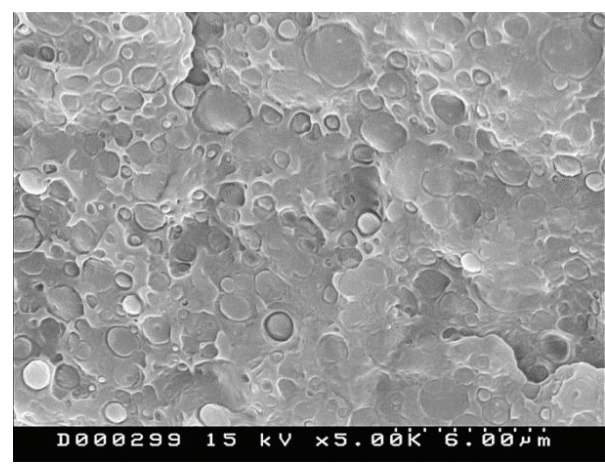

(d)

Figure 2: SEM micrographs of (a) 75/25, (b) 60/40, (c) 40/60, and (d) 25/75 gPP/PA12 blends.

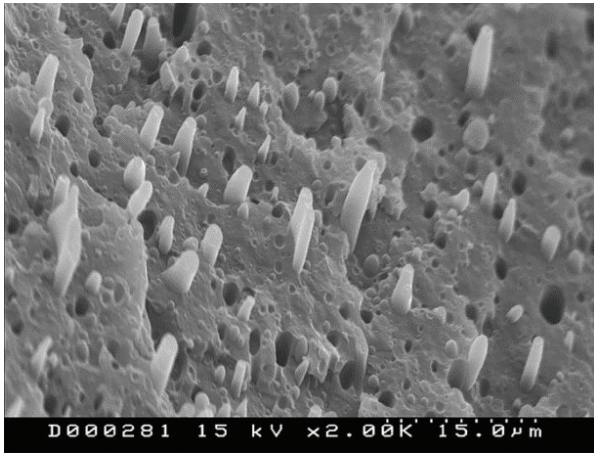

(a)

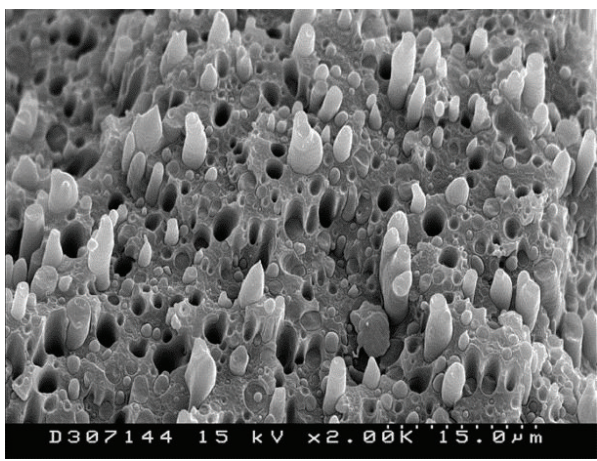

(c)

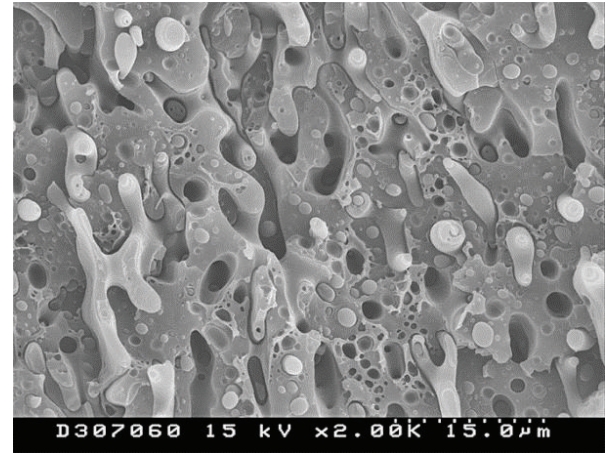

(b)

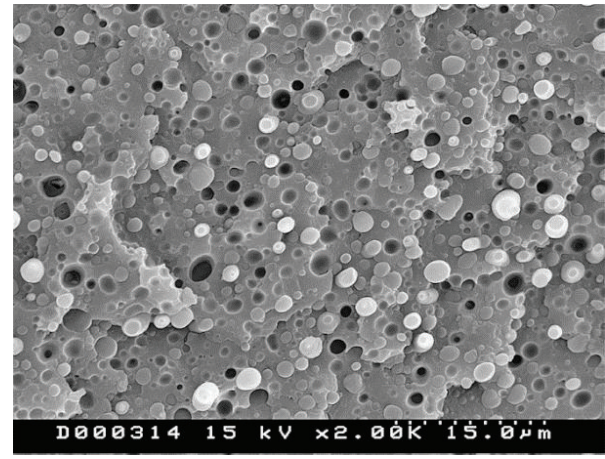

(d)

FIGURE 3: SEM micrographs of (a) 75/25, (b) 60/40, (c) 40/60, and (d) 25/75 PP/PA12 blends, taken with incidence angle of $40^{\circ}$ (a and c) and $0^{\circ}$ (b and d). 
of both the holes and the particles look very smooth with no adhered matrix residue. This strongly suggests poor interfacial adhesion. In addition, while the dispersed particles appear to be spherical in the micrographs taken at $0^{\circ}$, the images taken at $40^{\circ}$ prove that most of the particles are elongated in a direction perpendicular to the fracture surface, that is, parallel to the flow direction. This is caused by the flow during injection molding.

Figure 3(b) shows that the morphology of the $60 / 40 \mathrm{PP}$ blend was close to cocontinuity indicating that the phase inversion occurred close to that particular composition. To prove this, the melt viscosities were estimated by means of the torque for kneading of the components at the processing temperature $\left(200^{\circ} \mathrm{C}\right)$. The values were $945 \mathrm{~N} \cdot \mathrm{m}$ and $820 \mathrm{~N} \cdot \mathrm{m}$ for PP and PA12, respectively. Substituting these values in the equation for the composition for phase inversion [30], the volume composition for the phase inversion was $54 / 46$, which is consistent with the micrographs.

When gPP was used instead of PP (Figure 2), the change in morphology was drastic. This is because the compatibilized gPP blends show a very fine phase dispersion, typically in the $0.5-1 \mu \mathrm{m}$ range, despite the fact that a direct injection molding procedure was used. This indicates a decrease in interfacial tension and coalescence inhibition which is attributed to the formation of PP-g-PA12 copolymers resulting from the reaction of the PP-g-MA maleic groups with the terminal amine groups of PA12 [7, 31]; this takes place at the interfaces [32], leading to improved adhesion. The less pronounced compatibilization efficiency observed in the 25/75 gPP blend (Figure 2(d)) in comparison with the other gPP/PA12 compositions could be related to the fact that the amount of added PP-g-MA is relative to the PP phase, and thus its concentration is smaller increasing the PA12 content. In any case, the dispersed particles of Figure 2 are deeply embedded in the matrix. This, together with the fine dispersed phase size, proves that compatibilization occurred effectively in these blends despite fast and easy mixing by direct injection molding.

3.3. Mechanical Properties. Young's modulus-composition plot of the compatibilized gPP/PA12 blends, as well as that of the uncompatibilized PP/PA12 blends as a reference, is shown in Figure 4. Both plots are very similar, and for both the uncompatibilized and the compatibilized blends a positive deviation from linearity can be clearly seen. In the same blends obtained by kneading-compression $[8,9]$, negative deviations appeared. The positive deviations in Figure 4 led to absolute synergism in some compositions, with a higher modulus than in any of the neat components. In order to discuss the modulus behavior of the blends, the molecular orientation, a possible mixing-induced change in specific volume, and the crystallinity of the blend components must be considered. As the modulus behavior is almost identical for both gPP/PA12 and PP/PA12 blends, the discussion will only be made for gPP/PA12 blends.

The molecular orientation of the blends needs to be examined when attempting to explain the synergistic moduli, so birefringence measurements were taken and the results are

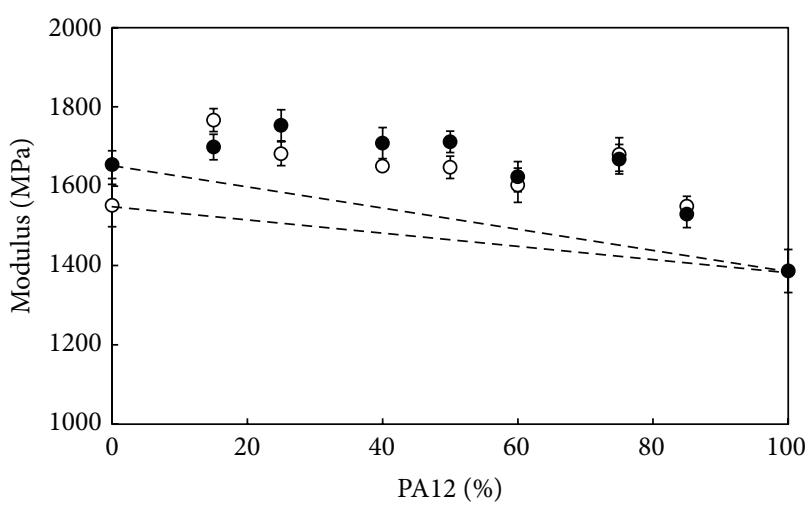

FIGURE 4: Young's modulus of the uncompatibilized PP/PA12 (O) and compatibilized gPP/PA12 ( ) blends, as a function of the PA12 content.

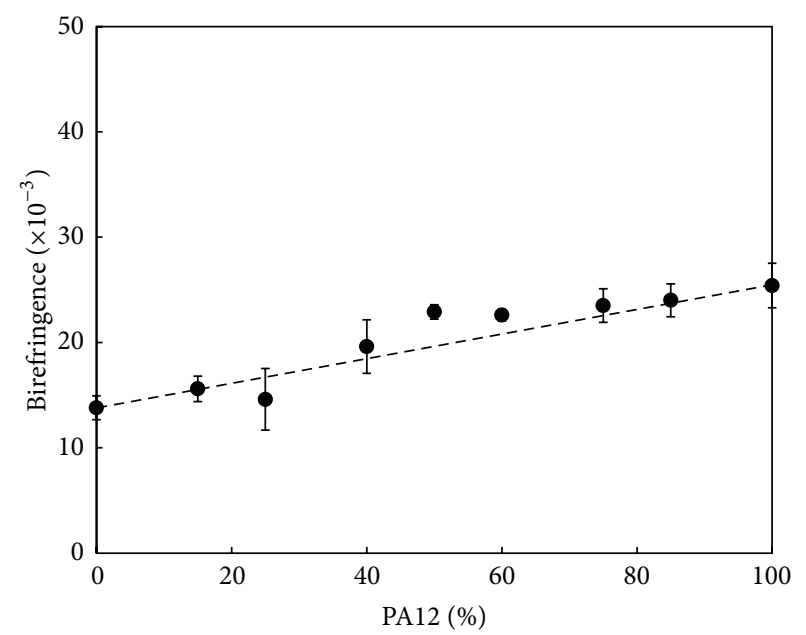

FIGURE 5: Birefringence of the gPP/PA12 blends, as a function of the PA12 content.

shown in Figure 5. The plot is practically linear, so a change in orientation on the blends was ruled out as an explanation for the behavior of Young's modulus. With respect to a mixinginduced change in specific volume, the density-composition plot was linear. However, further information about specific volume changes could not be obtained due to the crystalline nature of both components on the one hand and on the other because changes on the crystalline content of each component occurred upon blending.

Regarding the crystalline phases, the crystallinity of the PA12 in the blends was fairly constant with composition and slightly lower than that of the pure PA12. The crystallinity of gPP was constant in the gPP rich blends but increased in the PA12-rich compositions (Table 3). To discuss these results, we will first refer to the possible effects of crystallinity in the whole composition range and then will add additional considerations relative to the PA12-rich blends. Concerning the possible effects of the crystallinity, in blends of two crystallizable polymers, the physical properties may be altered not only by the blend composition and the phase morphology, but also by the crystallization behavior of each 
of the two components [30]. It is also known that (a) the crystallization of a dispersed (or continuous) phase is very different not only from that of the pure component, but also from the behavior of the continuous (or dispersed) phase; (b) a nucleating activity of both components on each other often takes place; this gives rise to smaller (and, then, larger amount of) crystals and may cause additional hindering of the amorphous phase; and (c) when the dispersion of crystalline particles becomes finer (by compatibilization, for instance), coincidental crystallization may occur [33] or be enhanced [34]. Therefore, the crystalline morphology of the components in this study very probably changes upon blending. Even though the effects of these morphological changes on the final properties are far from being understood, it is proposed that the behavior of the modulus of the blends is a result of the change of morphology of the dispersed crystalline phases.

In the PA12-rich blends, the previously observed new crystallization peak points to the presence of a different crystalline structure, and this change in morphology is further supported by the effects set out in the paragraph above. Moreover, there was a marked increase in the crystallinity of the gPP phase. It is known that marked changes in crystallinity usually influence the modulus values in polymers $[35,36]$ due to the greater presence of the amorphous phase. The change from $45 \%$ to $65 \%$, for example, is considerable enough to influence the modulus, as the crystalline phase is expected to increase its continuity. This makes the crystalline phase of the gPP the main contributor to the modulus, which is consistent with the modulus behavior observed.

The yield strength of the compatibilized gPP/PA12 blends was rather linear (Figure 6). This is consistent with the local nature of the yielding process that occurs in the structurally less resistant zone of the specimen. The ductility values of the gPP/PA12 blends are shown in Figure 7, together with those of the PP blends, as ductility is a measure of compatibility. As can be seen, ductility drastically improved over the whole composition range when gPP was used. The ductility of the 85/15 gPP blend does not appear in Figure 7 because it was higher than the elongation limit of the machine. In previous papers where PP/PA12 blends were obtained by compression molding $[8,9]$, the addition of a compatibilizer did not lead to an increase in ductility but rather to constant values or to a decrease. It must be taken into account that in reference [8] much larger particle sizes $(4 \mu \mathrm{m}$ in the 70/30 PP/PA12 compatibilized blend) were present. The increase in ductility in this paper is most likely to be the result of and is indeed attributed to the decrease in the dispersed phase size and the increase in interfacial adhesion, both due to the compatibilizing effect of the PP-g-PA12 copolymers formed in situ during processing.

\section{Conclusions}

The addition of 20\% PP-g-MA to the PP allowed gPP/PA12 compatible blends to be obtained by direct injection molding throughout the whole composition range. No change was observed in the $T_{g}$ of the PA12 phase, but that of gPP showed a slight increase in PA12-rich blends. Although no change

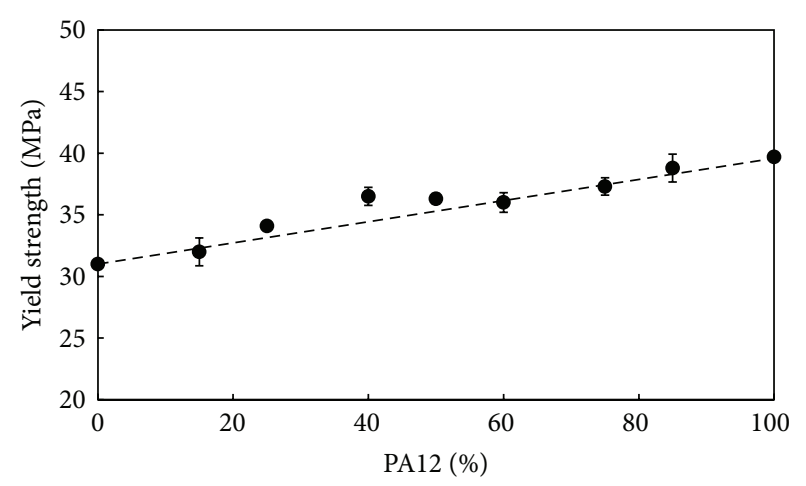

FIGURE 6: Yield strength of the compatibilized gPP/PA12 blends, as a function of the PA12 content.

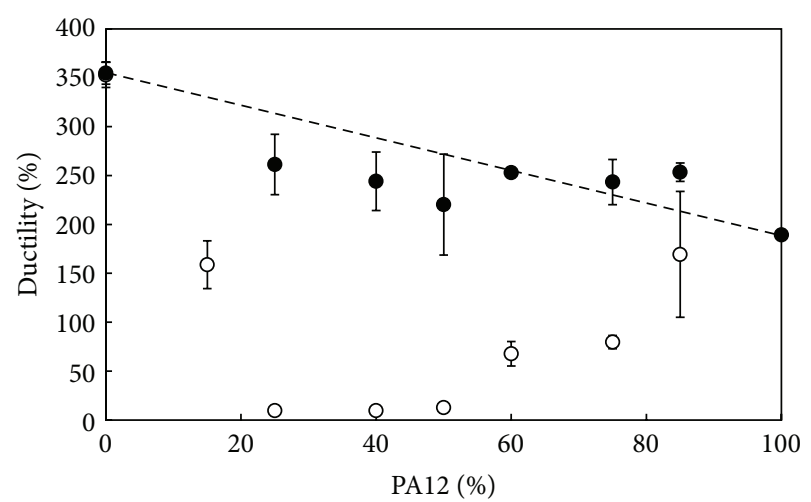

FIGURE 7: Ductility of the uncompatibilized PP/PA12 $(\mathrm{O})$ and compatibilized gPP/PA12 ( ) blends, as a function of the PA12 content.

was observed in the two $T_{m} s$ or the $T_{c}$ of the PA12 either, a nucleating effect of the PA12 took place during the cooling crystallization of the gPP. There was a second crystallization peak of gPP in the PA12-rich blends, which indicates a change in the crystalline morphology of the gPP upon blending. The crystallinity of the PA12 decreased slightly in the compatible blends. That of gPP was constant in gPP-rich blends, but it increased significantly in PA12-rich blends.

The addition of the compatibilizer led to a clear reduction in the particle size (roughly from $2-5 \mu \mathrm{m}$ to $0.5-1 \mu \mathrm{m}$ ) thanks to the formation of PP-g-PA12 copolymers at the interfaces. This resulted in a very considerable increase in ductility. This together with the decrease in the dispersed phase is a clear indication of compatibilization.

Young's modulus of the blends showed synergistic behavior throughout the composition range. This is believed to be due to a change in the crystalline morphology of the blends and, in the case of the PA12-rich blends, it was also due to the significant increase (from $45 \%$ to $65 \%$ ) in the crystallinity of the gPP phase which increases its continuity and its contribution to the modulus.

\section{Conflict of Interests}

The authors declare that there is no conflict of interests regarding the publication of this paper. 


\section{Acknowledgments}

The financial support of the Basque Government (Project IT-611-13) and of the University of the Basque Country (UFI 11/56) is gratefully acknowledged. Nora Aranburu also acknowledges the Basque Government for the award of a grant for the development of this work.

\section{References}

[1] D. Wang, Y. Li, X.-M. Xie, and B.-H. Guo, "Compatibilization and morphology development of immiscible ternary polymer blends," Polymer, vol. 52, no. 1, pp. 191-200, 2011.

[2] D. R. Paul and C. B. Bucknall, Polymer Blends, Wiley-Interscience, New York, NY, USA, 2000.

[3] S. Datta and D. J. Lohse, Polymeric Compatibilizers: Uses and Benefits in Polymer Blends, Hanser Publishers, Munich, Germany, 1996.

[4] G. Jiang, H. Wu, and S. Guo, "Reinforcement of adhesion and development of morphology at polymer-polymer interface via reactive compatibilization: a review," Polymer Engineering and Science, vol. 50, no. 12, pp. 2273-2286, 2010.

[5] A. Sacchi, L. Di Landro, M. Pegoraro, and F. Severini, "Morphology of isotactic polypropylene-polyamide 66 blends and their mechanical properties," European Polymer Journal, vol. 40, no. 8, pp. 1705-1713, 2004.

[6] J. Nagel, D. Scheidler, B. Hupfer et al., "Investigations on the formation of composites by injection molding of PA6 and different grafted polypropylenes and their blends," Journal of Applied Polymer Science, vol. 100, no. 4, pp. 2992-2999, 2006.

[7] N. Abacha and S. Fellahi, "Synthesis of polypropylene-graftmaleic anhydride compatibilizer and evaluation of nylon 6/polypropylene blend properties," Polymer International, vol. 54, no. 6, pp. 909-916, 2005.

[8] S. Jose, B. Francis, S. Thomas, and J. Karger-Kocsis, "Morphology and mechanical properties of polyamide 12/polypropylene blends in presence and absence of reactive compatibiliser," Polymer, vol. 47, no. 11, pp. 3874-3888, 2006.

[9] S. Jose, S. V. Nair, S. Thomas, and J. Karger-Kocsis, "Effect of reactive compatibilisation on the phase morphology and tensile properties of PA12/PP blends," Journal of Applied Polymer Science, vol. 99, no. 5, pp. 2640-2660, 2006.

[10] J. Zhang, P. J. Cole, U. Nagpal, C. W. Macosko, and T. P. Lodge, "Direct correlation between adhesion promotion and coupling reaction at immiscible polymer-polymer interfaces," The Journal of Adhesion, vol. 82, no. 9, pp. 887-902, 2006.

[11] M. Jaziri, N. Barhoumi, V. Massardier, and F. Mélis, "Blending PP with PA6 industrial wastes: effect of the composition and the compatibilization," Journal of Applied Polymer Science, vol. 107, no. 6, pp. 3451-3458, 2008.

[12] D. Li, D. Jia, and P. Zhou, "Compatibilization of polypropylene/nylon 6 blends with a polypropylene solid-phase graft," Journal of Applied Polymer Science, vol. 93, no. 1, pp. 420-427, 2004.

[13] C.-H. Jung, J.-H. Choi, Y.-M. Lim et al., "Preparation of polypropylene compatibilizer by radiation grafting and its effect on PP/Nylon 6 blend," Macromolecular Symposia, vol. 249-250, pp. 573-579, 2007.

[14] S. Jose, S. Thomas, P. K. Biju, P. Koshy, and J. Karger-Kocsis, "Thermal degradation and crystallisation studies of reactively compatibilised polymer blends," Polymer Degradation and Stability, vol. 93, no. 6, pp. 1176-1187, 2008.
[15] A. Tedesco, R. V. Barbosa, S. M. B. Nachtigall, and R. S. Mauler, "Comparative study of PP-MA and PP-GMA as compatibilizing agents on polypropylene/nylon 6 blends," Polymer Testing, vol. 21, no. 1, pp. 11-15, 2002.

[16] P. Agrawal, S. I. Oliveira, E. M. Araújo, and T. J. A. Melo, "Effect of different polypropylenes and compatibilizers on the rheological, mechanical and morphological properties of nylon 6/PP blends," Journal of Materials Science, vol. 42, no. 13, pp. 5007-5012, 2007.

[17] A. Valenza and D. Acierno, “Ternary blends of nylon 12/polypropylene/modified polypropylene: influence of functional groups of the modified polypropylene," European Polymer Journal, vol. 30, no. 10, pp. 1121-1126, 1994.

[18] G. M. Shashidhara, D. Biswas, B. S. Pai, A. K. Kadiyala, G. S. W. Feroze, and M. Ganesh, "Effect of PP-g-MAH compatibilizer content in polypropylene/nylon-6 blends," Polymer Bulletin, vol. 63, no. 1, pp. 147-157, 2009.

[19] A. Tedesco, P. F. Krey, R. V. Barbosa, and R. S. Mauler, "Effect of the type of nylon chain-end on the compatibilization of PP/PPGMA/nylon 6 blends," Polymer International, vol. 51, no. 2, pp. 105-110, 2002.

[20] I. Y. Phang, T. Liu, A. Mohamed et al., "Morphology, thermal and mechanical properties of nylon 12/organoclay nanocomposites prepared by melt compounding," Polymer International, vol. 54, no. 2, pp. 456-464, 2005.

[21] T. Tang, Z. Lei, X. Zhang, H. Chen, and B. Huang, "Studies on simultaneous crystallization of polypropylene/nylon 12 blends," Polymer, vol. 36, no. 26, pp. 5061-5063, 1995.

[22] T. Tang, Z. Lei, and B. Huang, "Studies on morphology and crystallization of polypropylene/polyamide 12 blends," Polymer, vol. 37, no. 15, pp. 3219-3226, 1996.

[23] T. McNally, W. R. Murphy, C. Y. Lew, R. J. Turner, and G. P. Brennan, "Polyamide-12 layered silicate nanocomposites by melt blending," Polymer, vol. 44, no. 9, pp. 2761-2772, 2003.

[24] Y. Wu, Y. Yang, B. Li, and Y. Han, "Reactive blending of modified polypropylene and polyamide 12: effects of compatibilizer content on crystallization and blend morphology," Journal of Applied Polymer Science, vol. 100, no. 4, pp. 3187-3192, 2006.

[25] N. Torres, J. J. Robin, and B. Boutevin, "Study of compatibilization of HDPE-PET blends by adding grafted or statistical copolymers," Journal of Applied Polymer Science, vol. 81, no. 10, pp. 2377-2386, 2001.

[26] S. M. B. Nachtigall, A. H. O. Felix, and R. S. Mauler, "Blend compatibilizers based on silane- and maleic anhydride-modified polyolefins," Journal of Applied Polymer Science, vol. 88, no. 10, pp. 2492-2498, 2003.

[27] N. Aranburu and J. I. Eguiazabal, "Compatible blends of polypropylene with an amorphous polyamide," Journal of Applied Polymer Science, vol. 127, no. 6, pp. 5007-5013, 2013.

[28] Q. Wei, D. Chionna, and M. Pracella, "Reactive compatibilization of PA6/LDPE blends with glycidyl methacrylate functionalized polyolefins," Macromolecular Chemistry and Physics, vol. 206, no. 7, pp. 777-786, 2005.

[29] J. Piglowski, I. Gancarz, M. Wlaźlak, and H.-W. Kammer, "Crystallization in modified blends of polyamide and polypropylene," Polymer, vol. 41, no. 18, pp. 6813-6824, 2000.

[30] L. A. Utracki, Polymer Blends Handbook, Kluwer Academic Publishers, Dordrecht, The Netherlands, 2002.

[31] H. Liu, T. Xie, Y. Zhang, Y. Ou, and G. Yang, "Phase morphology development in PP/PA6 blends induced by a maleated thermoplastic elastomer," Journal of Polymer Science, Part B: Polymer Physics, vol. 44, no. 7, pp. 1050-1061, 2006. 
[32] J. Duvall, C. Sellitti, V. Topolkaraev, A. Hiltner, E. Baer, and C. Myers, "Effect of compatibilization on the properties of polyamide 66/polypropylene (75/25 wt/wt) blends," Polymer, vol. 35, no. 18, pp. 3948-3957, 1994.

[33] S. J. Park, B. K. Kim, and H. M. Jeong, "Morphological, thermal and rheological properties of the blends polypropylene/nylon6, polypropylene/nylon-6/(maleic anhydride-g-polypropylene) and (maleic anhydride-g-polypropylene)/nylon-6," European Polymer Journal, vol. 26, no. 2, pp. 131-136, 1990.

[34] H.-S. Moon, B.-K. Ryoo, and J.-K. Park, "Concurrent crystallization in polypropylene/nylon-6 blends using maleic anhydride grafted polypropylene as a compatibilizing agent," Journal of Polymer Science. Part B: Polymer Physics, vol. 32, no. 8, pp. 1427-1435, 1994.

[35] A. Arzak, J. I. Eguiazabal, and J. Nazabal, "Biphasic compatible blends from injection-molded poly(ether ether ketone)/polysulfone," Journal of Applied Polymer Science, vol. 65, no. 8, pp. 1503-1510, 1997.

[36] L. E. Sanchez-Cadena, B. Alvarado-Tenorio, A. Romo-Uribe, B. Campillo, O. Flores, and H. Yao, "Hot-pressed boards based on recycled high-density polyethylene tetrapack: mechanical properties and fracture behavior," Journal of Reinforced Plastics and Composites, vol. 32, no. 23, pp. 1779-1792, 2013. 

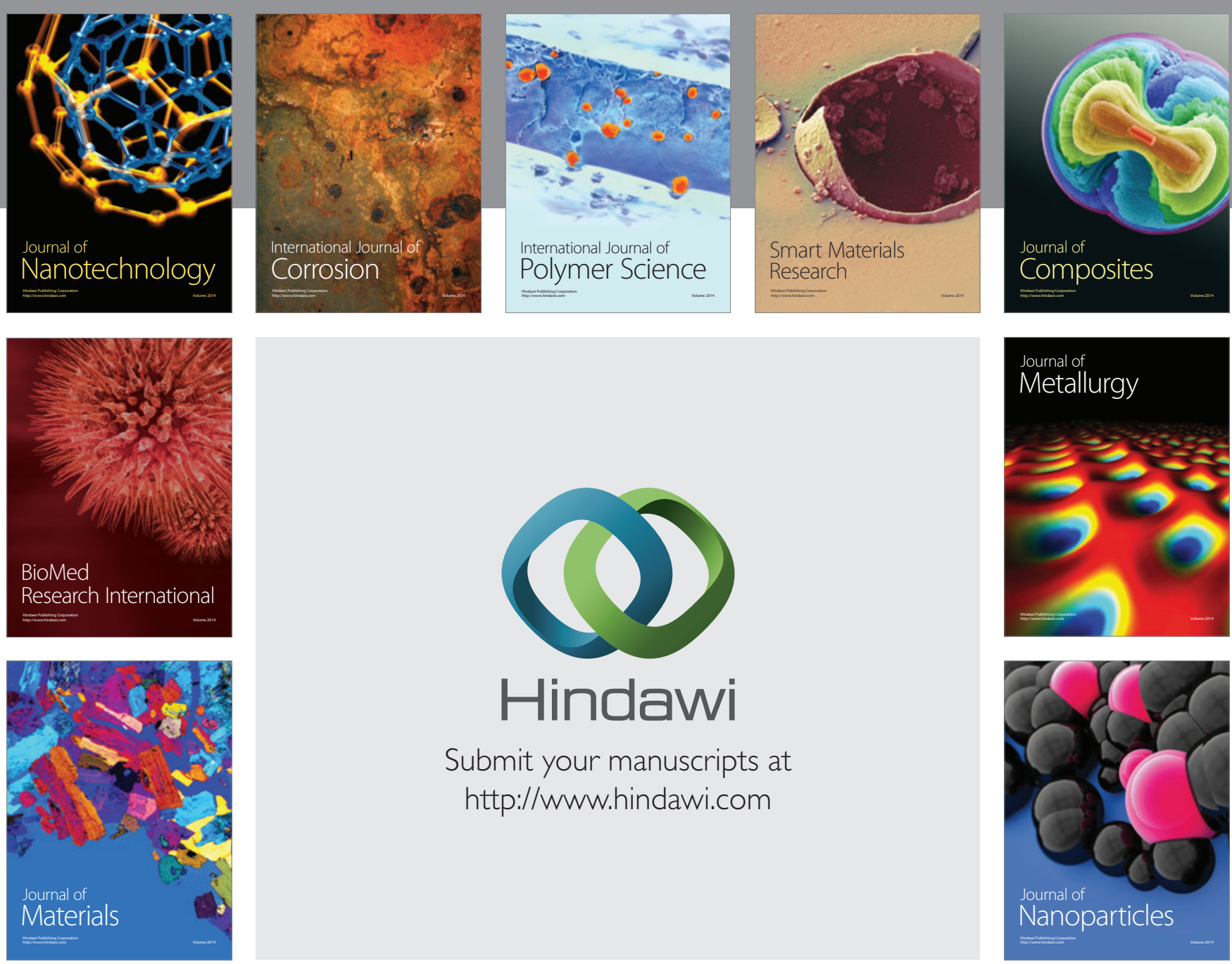

Submit your manuscripts at http://www.hindawi.com
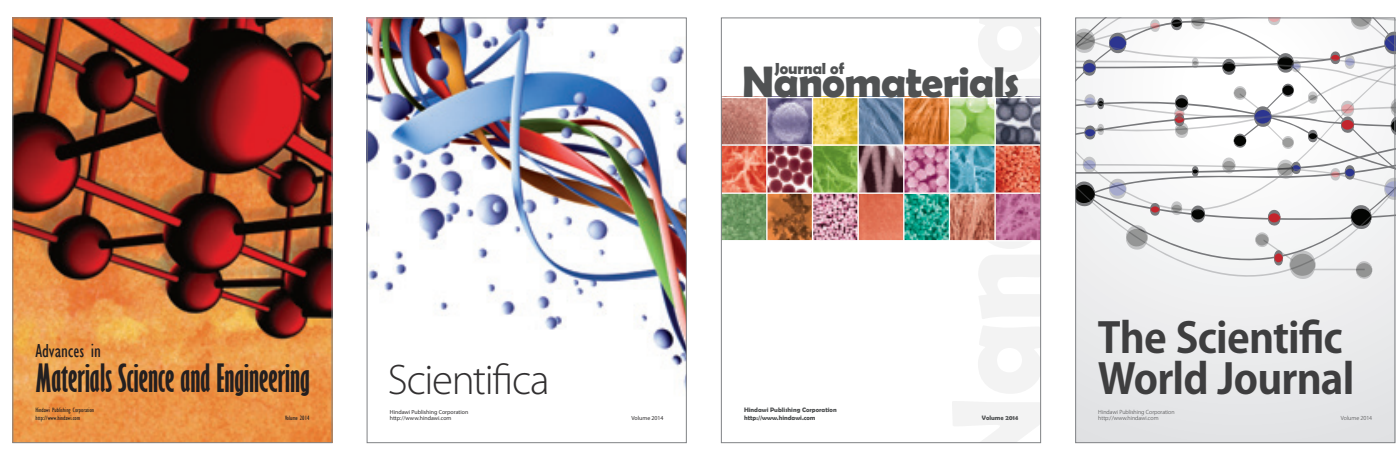

\section{The Scientific World Journal}
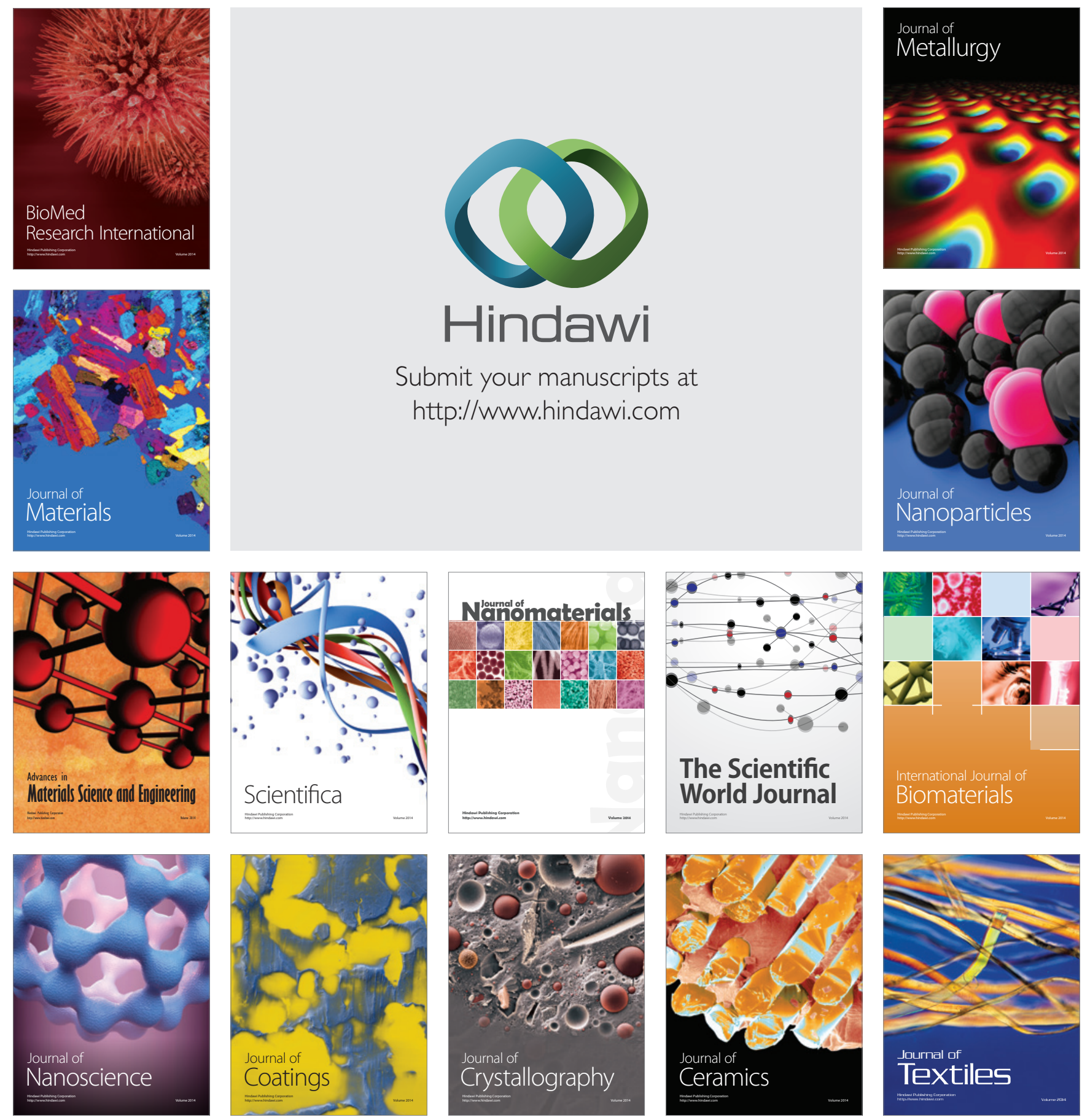